\title{
Association of TP53 codon 72 genotype polymorphism and environmental factors with esophageal squamous cell carcinoma in the Mongolian population of the Chinese region of Inner Mongolia
}

\author{
MING LI ${ }^{1,2^{*}}$, DAPENG WANG ${ }^{2 *}$, YUMIN WANG $^{3}$, GUILI SUN $^{2}$, \\ WANLI SONG ${ }^{2,4}$, BIN ZHANG ${ }^{2}$ and BURENBATU BORJIGIN ${ }^{2}$
}

\author{
${ }^{1}$ Department of Oncology, Ezhou Central Hospital, Ezhou, Hubei 436000; ${ }^{2}$ Department of Oncology, Affiliated Hospital \\ of Inner Mongolia University for The Nationalities, Tongliao, Inner Mongolia 028000; ${ }^{3}$ Department of Oncology, \\ Affiliated Hospital of Chifeng University, Chifeng, Inner Mongolia 024005; ${ }^{4}$ Department of Neurosurgery, \\ People's Hospital of ZheCheng, ZheCheng County in Shangqiu, Shangqiu, Henan 476200, P.R. China
}

Received November 12, 2015; Accepted April 13, 2017

DOI: $10.3892 / \mathrm{ol} .2017 .6374$

\begin{abstract}
The present study analyzed the association of tumor protein p53 (TP53) Pro72Arg polymorphism with esophageal squamous cell carcinoma (ESCC) in the Mongolian population of Tongliao (Inner Mongolia, China). Restriction fragment length polymorphism-polymerase chain reaction was used to detect the genotype distribution of TP53 Pro72Arg polymorphism in 100 patients with ESCC and 50 healthy controls from the same population. Besides, the correlation between ESCC in Mongolian patients and various factors such as age, sex, cigarette smoking and alcohol consumption was analyzed. $\chi^{2}$ test revealed significant associations between alcohol consumption ( $\mathrm{P}=0.00006)$ and cigarette smoking $(\mathrm{P}=0.00076)$ and ESCC in Mongolian patients. Notably, the Pro72 allele was significantly enriched in patients with ESCC compared with its abundance in the healthy control group, and the genotype of Pro/Arg on p53 codon 72 was confirmed to exhibit a significant correlation with ESCC in Mongolian patients. The present study demonstrated that alcohol drinking and cigarette smoking were risk factors for ESCC in the Mongolian population. Mongolian patients who carry the partocular genotype of Arg/Pro or Pro/Pro on p53 codon 72 may be more likely to develop ESCC. Compared with the p53 codon 72 genotype Arg/Arg, the TP53 Pro72 allele increased the risk of ESCC in Mongolian patients by 1.659 -fold.
\end{abstract}

Correspondence to: Professor Guili Sun, Department of Oncology, Affiliated Hospital of Inner Mongolia University for the Nationalities, 1742 East Avenue of Huolin Rive, Tongliao, Inner Mongolia 028000, P.R. China

E-mail: mdfysgl@sina.com

*Contributed equally

Key words: ESCC, Mongolian, p53, cigarette smoking, alcohol drinking, polymorphism

\section{Introduction}

Esophageal squamous cell carcinoma (ESCC) is one of the most common malignant tumors and the eighth most frequently diagnosed cancer in the world (1). It is estimated that almost $50 \%$ of ESCC cases occur in China, particularly in Hebei, Henan and North China (2,3). The development of ESCC is a complex process, and numerous environmental factors may contribute to ESCC, including diet, infection, poor nutrition status, low intake of fruits and vegetables, and particularly tobacco smoking and alcohol consumption $(4,5)$. However, certain individuals who are exposed to the same risk factors may have different susceptibility to ESCC, which shows that genetic factors are important in the development of ESCC (6). Besides, the differences in genetic factors among patients with ESCC may be associated with geographic and ethnic characteristics (7).

Tongliao is the most concentrated area of Mongolian population in the Inner Mongolia Autonomous Region of China, and even in the whole of China (8). These Mongolian inhabitants have acquired the habit of consuming diets with high salt and calorie content, due to the particular geographic and climate characteristics of this region (9). In recent years, due to the absence of early ESCC symptoms, traditional screening and treatment methods have not greatly increased the survival of patients with ESCC (10).

In Tongliao, there is only a small percentage of individuals who suffered from esophageal cancer, despite the fact that all residents share similar environmental risk factors (11). This suggested that genetic factors such as genetic polymorphisms may serve a key role in the pathogenesis of ESCC.

Certain studies have indicated that $>50 \%$ of patients with cancer have p53 gene mutations during the occurrence and development of human cancer (12). In China, certain studies demonstrated that the genotype Pro/Pro of p53 is a risk factor for ESCC in Chaoshan in Guangdong, Linzhou in Henan and Yanting in Sichuan, but in other places such as Hebei, Cixian or Shexian, the genotype Pro/Pro of p53 is not a risk factor (7). Not only is the occurrence of esophageal cancer associated 
with the region where a population lives, but it is also closely associated with ethnicity, since the Kazakh ethnic group of Xinjiang in China has a high incidence of ESCC (13).

Studies about the correlation between ESCC in Mongolian patients and susceptibility genes for ESCC are rarely reported. The identification of genetic susceptible factors for ESCC in Mongolian patients will have broad implications in understanding the pathogenesis of ESCC in the Mongolian population, and will aid early detection, diagnosis and therapy.

\section{Patients and methods}

Subjects. The present study was approved by the Ethics Committee of the Affiliated Hospital of Inner Mongolia University for the Nationalities (Tongliao, China). Written informed consent was obtained from all participants prior to the study via an institutional patient consent form. The study was conducted in accordance with the regulations of the Inner Mongolia University for the Nationalities.

A total of 100 Mongolian patients with surgically resectable thoracic ESCC who had received curative esophagectomy and lymph node dissection at the Affiliated Hospital of Inner Mongolia University for the Nationalities between April 2013 and June 2014 were enrolled in the present study. According to the collected information, all patients were permanent residents of Tongliao, in Southeastern Inner Mongolia. None of the study participants received neoadjuvant therapy prior to hospital admission. Patient clinicopathological characteristics are summarized in Table I.

Additionally, 50 healthy Mongolian individuals, whose physical health had been verified at the Physical Examination Center of the Affiliated Hospital of Inner Mongolia University for the Nationalities, were randomly selected as control group. The control group and ESCC group were all recruited from pastoral areas of Tongliao city in inner Mongolia. The control subjects were frequency-matched to the patients by age $( \pm 5$ years) and sex. Statistical analysis on the general information of the two groups, was performed, and results are summarized in Table II.

Pathological diagnosis. All ESCC patients had a definite pathological diagnosis based on the stage of histopathological slice and differentiation of tumor cells. Accordingly, the patients were divided into three grades: Poorly, moderately and highly differentiated SCC. Tissue samples were stained with hematoxylin and eosin. Three representative histopathological slice images of different grades are shown in Fig. 1.

Detection method and result evaluation. Blood samples were collected in EDTA-coated tubes with the SiMax ${ }^{\mathrm{TM}}$ Genomic DNA Extraction kit (SBS Genetech Co., Ltd., Beijing, China) to extract the genomic DNA from the peripheral blood leukocyte pellet of the two groups. Genomic DNA was isolated and purified from all subjects, and next subjected to $\beta$-globin polymerase chain reaction (PCR) analysis to detect the existence of human DNA in the sample. Those $\beta$-globin-PCR negative samples were excluded from the analysis. $\beta$-globin primers were designed to verify the quality and quantity of the DNA template. PCR primers were also synthesized according to the p53 gene sequence published
Table I. Patient characteristics.

Characteristics

$\mathrm{N}($ total $\mathrm{n}=100)$

Sex (male/female)

Age/years (mean \pm standard deviation)

Tumor location (upper/middle/lower)

$54.32 \pm 7.40$

$9 / 52 / 39$

TNM classification

$\mathrm{T} 1 / \mathrm{T} 2 / \mathrm{T} 3 / \mathrm{T} 4$

$10 / 20 / 43 / 27$

$\mathrm{N} 0 / \mathrm{N} 1 / \mathrm{N} 2 / \mathrm{N} 3$

$54 / 31 / 12 / 3$

Grade (I/II/III)

$19 / 19 / 62$

Histopathological diagnosis

PDSCC

43

MDSCC

39

HDSCC

18

TNM, tumor-node-metastasis; PDSCC, poorly differentiated squamous cell carcinoma; MDSCC, moderately differentiated squamous cell carcinoma; HDSCC, highly differentiated squamous cell carcinoma.

on GenBank (http://www.ncbi.nlm.nih.gov/WebSub/?tool= genbank) (Fig.2) by Beijing Genomics Institute (Beijing, China), and were designed by Primer 5.0 software (Beijing Genomics Institute, Beijing, China). p53 gene was amplified by PCR, and the procedure included an initial melting step of $5 \mathrm{~min}$ at $94^{\circ} \mathrm{C}$, followed by 35 cycles of denaturation at $94^{\circ} \mathrm{C}$ for $60 \mathrm{sec}$, annealing at $60^{\circ} \mathrm{C}$ for $60 \mathrm{sec}$ and extension at $72^{\circ} \mathrm{C}$ for $60 \mathrm{sec}$, and preservation at $4^{\circ} \mathrm{C}$. The PCR mixture $(50 \mu \mathrm{l})$ contained 2 ng template DNA, $0.5 \mu \mathrm{l}$ Taq enzyme (5 U/ $\mu \mathrm{l}$ ) (Treasure Bioengineering Co., Ltd., Dalian, China), $2.5 \mu \mathrm{l}$ 10X PCR Buffer $\left(\mathrm{Mg}^{2+}\right)$ (Hamilton's product, Bonaduz, Switzerland), $1.5 \mu \mathrm{l}(0.2 \mu \mathrm{mol} / \mathrm{l})$ forward primer, $1.5 \mu \mathrm{l}$ reverse primer, $4 \mu \mathrm{l}$ (200 umol/l) deoxynucleotide triphosphates and $\leq 25 \mu$ l double distilled (dd) $\mathrm{H}_{2} \mathrm{O}$. The PCR product was detected through electrophoresis (3\% agarose gel) performed at $90 \mathrm{~V} / \mathrm{cm}$ for $40 \mathrm{~min}$ and after the electrophoresis, the results were observed and photographed under the ultraviolet light of the gel imaging system, followed by evaluation with the UV Transmission Analyzer (Shanghai Spectrum Instrument Co. Ltd, Shanghai, China).

AccII restriction enzyme was used to digest the p53-amplified product of $\mathrm{PCR}$ at $37^{\circ} \mathrm{C}$. The enzymatic digestion reaction (20 $\mu \mathrm{l})$ contained $10 \mu \mathrm{l}$ PCR-amplified product, $1 \mu \mathrm{l}$ AccII (10 U/ $/ \mu \mathrm{l}), 1 \mu \mathrm{l} 10 \mathrm{X}$ buffer and $8 \mu \mathrm{l}$ sterilized $\mathrm{ddH}_{2} 0$. The digested product $(8 \mu \mathrm{l})$ was dissolved in $1 \mathrm{X}$ Tris base, acetic acid and EDTA solution, and then electrophoresed in a $3 \%$ agarose gel for $40 \mathrm{~min}$ at $90 \mathrm{~V}$. The results were observed and photographed under ultraviolet light in a gel imaging system (Figs. 3 and 4).

In order to test the reliability of the assay, 30 samples with identical mutations were randomly selected to be re-tested. Sequence analysis was performed with the BigDye Terminator Cycle Sequencing kit (Thermo Fisher Scientific, Inc., Waltham, MA, USA) and the ABI PRISM 3730 DNA Analyzer (Applied Biosystems; Thermo Fisher Scientific, Inc.) (Fig. 4). 

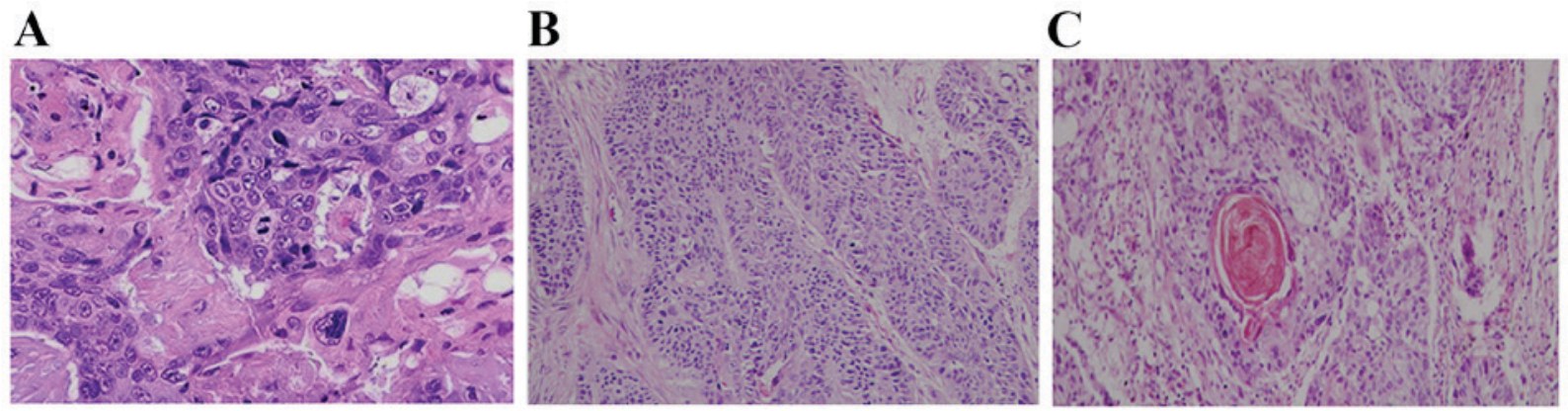

Figure 1. Three representative histopathological slice images of three different pathology stages of ESCC are shown: (A) Poorly differentiated SCC (H\&E staining; magnification, x400); (B) moderately differentiated SCC (H\&E staining; magnification, x200); and (C) highly differentiated SCC (H\&E staining; magnification, x200). H\&E, hematoxylin and eosin; SCC, squamous cell carcinoma.

Statistical analysis. Pearson's $\chi^{2}$ test was used to examine the differences in age, sex, cigarette smoking, alcohol consumption, allele polymorphism and genotype distribution between case and control subjects. Hardy-Weinberg goodness-of-fit test was used to analyze the different genotype distribution equilibrium for the same polymorphic site. The statistical software SPSS 15 (SPSS, Inc., Chicago, IL, USA) was used to analyze the data. Phase 2.1 software (http://www.stat .washington.edu/stephens/home.html) was used to analyze the haplotype, and the conditional logistic regression model was used to analyze the correlation between gene polymorphisms and haplotypes and susceptibility to ESCC. The association between mutant genotype or allele polymorphism and esophageal cancer risk was calculated by odds ratio (OR) with $95 \%$ confidence interval $(\mathrm{CI}) . \mathrm{P}<0.05$ was considered to indicate a statistically significant difference.

\section{Results}

Characteristics of the study subjects. Based on the information of clinical records (Table II), the distribution of the two groups regarding factors such as sex, age, cigarette smoking and alcohol consumption was analyzed. The results revealed that the age distribution of the two groups was adequately matched $\left(\chi^{2}=3.211, \mathrm{P}=0.073\right)$. According to the sex distribution, no significant difference was observed in patients with ESCC vs. controls $\left(\chi^{2}=0.033, \mathrm{P}=0.857\right)$. However, both the distribution of alcohol consumption and cigarette smoking had a significant difference in ESCC vs. control groups $\left(\chi^{2}=15.992, \mathrm{P}<0.001\right.$ and $\chi^{2}=11.344, \mathrm{P}=0.001$, respectively), which indicated that alcohol drinking and cigarette smoking were high-risk factors for ESCC in the Mongolian population.

Tumor protein $p 53$ (TP53) Pro72 allele is enriched in patients with ESCC but not in the control group. The distribution of p53 genotypes is different in the two groups. In the ESCC group, 25.0, 41.7 and 33.3\% of patients had Pro/Pro, Pro/Arg and Arg/Arg genotypes, respectively, compared with 14.0, 30.0 and $56.0 \%$ of subjects, respectively, in the control group, which indicated that the distribution of genotypes was statistically significant $\left(\chi^{2}=7.49, \mathrm{P}<0.05\right)$ and that the p53 genotype is associated with ESCC in Mongolian patients. The genotype $\mathrm{Arg} / \mathrm{Pro}$ was the most abundant in the ESCC group, while in the control group, the most abundant genotype was Arg/Arg.
This demonstrates that Arg/Pro is involved in the occurrence of ESCC in the Mongolian population. The frequency of Arg and Pro alleles in the two groups was analyzed by $\chi^{2}$ test, which revealed $\chi^{2}=6.165, P=0.013$, indicating that the two alleles served different roles in the occurrence of ESCC in Mongolian patients (Table III).

TP53 Pro72 allele increases the risk of ESCC in Mongolian patients. In order to unravel the role of allele mutations in p53 codon 72 on ESCC in Mongolian patients, an unconditional logistic regression model was used to estimate the association between genotypes and the risk of ESCC. A risk analysis was conducted in which genotypes such as Pro/Pro and Arg/Pro were regarded as the exposure factors, and Arg/Arg was regarded as the non-exposure factor (Table IV). By comparing both types of factors, the allele mutations of p53 codon 72 appeared to be associated with an increased risk of developing ESCC (OR=1.659, 95\% $\mathrm{CI}=1.112-2.474)$, compared with the risk exhibited by the Arg/Arg genotype.

\section{Discussion}

To the best of our knowledge, the present study is the first report showing the association between TP53 codon 72 polymorphisms and the risk of ESCC in a Mongolian population. It was concluded that TP53 codon 72 polymorphisms were associated with an increased risk of developing ESCC through the present hospital-based case-control analysis on a Mongolian population. Besides, it was demonstrated that cigarette smoking and alcohol consumption could markedly increase the risk of ESCC.

It is known that passive smoking is a major risk factor for lung cancer, but a recent study conducted on passive smoking demonstrated that it was also significantly associated with increased risk of ESCC and breast cancer in women (14). The present study also observed that cigarette smoking and alcohol consumption are risk factors for ESCC, which is in agreement with previous studies (15-17). A possible explanation for these findings is that alcohol drinking and cigarette smoking cause irreversible genetic damage, or inhibit the repair mechanisms of genetic damage $(2,18)$. Besides, cigarette smokers or alcohol drinkers with p53 Arg/Arg or Arg/Pro could have a higher risk of infection by human 


\section{5'--GGGCTGGGGACCTGGAGGGCTGGGGGGCTGGGGGGCTGAGGACCTGGTCCTC TGACTGCTCTTTTCACCCATCTACAGTCCCCCTTGCCGTCCCAAGCAATGGATGAT TTGATGCTGTCCCCGGACGATATTGAACAATGGTTCACTGAAGACCCAGGTCCAG ATGAAGCTCCCAGAATGCCAGAGGCTGCTCCCCCCGTGGCCCCTGCACCAGCAGC TCCTACACCGGCGGCCCCTGCACCAGCCCCCTCCTGGCCCCTGTCATCTTCTGTCC CTTCCCAGAAAACCTACCAGGGCAGCTACGGTTTCCGTCTGGGCTTCTTGCATTCT GGGACAGCCAAGTCTGTGACTTGCACGGTCAGTTGCCCTGAGGGGCTGGCTTCCA TGAGACTTCAATGCCTGGCCGTATCCCCCTGCATTTCTTTTGTTTGGAACTTTGGG ATTCCTCTTCACCCTTTGGCTTCCTGTCAGTGTTTTTTTATA--3' Forward primer: 5-CAACACCATAGCAGTAGCAGC-3 Reverse primer: 5-CAGCCTCTCCTTCATACAGCC-3}

Figure 2. Polymerase chain reaction primer design. The sequence of the p53 gene in the human chromosome $17 \mathrm{p} 13.1$ is displayed, according to the p53 gene sequence published on GenBank. The primers were designed by Primer 5.0 software and synthesized by Beijing Genomics Institute.

$\mathbf{A}$

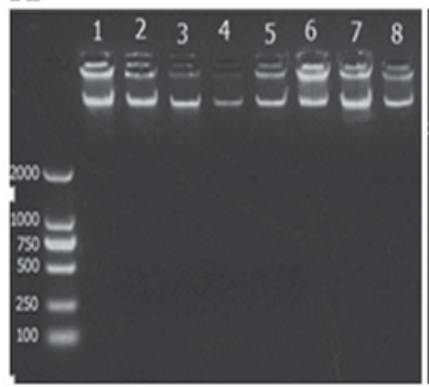

B

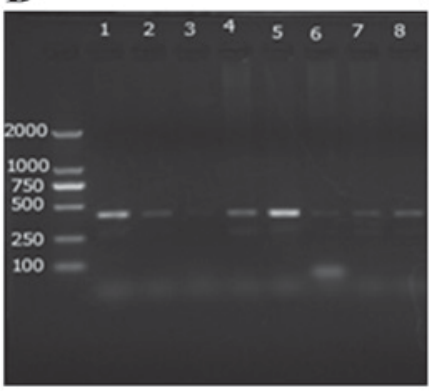

C

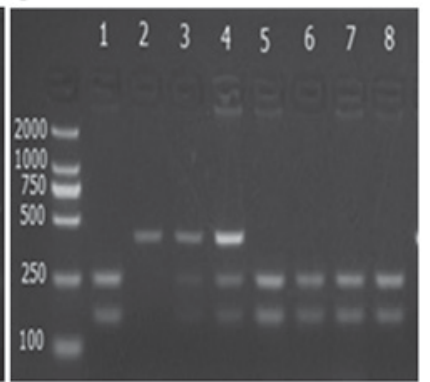

Figure 3. Representative images of PCR. The left lanes of each gel image represent size markers. (A) Representative image of the genomic DNA of the present Mongolian cohort. (B) Representative image of the PCR product of p53-gene amplification. (C) Restriction fragment length polymorphism-PCR analysis of p53 codon 72 polymorphisms. All samples represent PCR products digested with the restriction enzyme AccII. Lanes 1-8 correspond to different patients with esophageal squamous cell carcinoma. Samples 1 and 5-8 are Arg/Arg; samples 2 and 3 are Pro/Pro; and sample 4 is Pro/Arg. PCR, polymerase chain reaction.

A

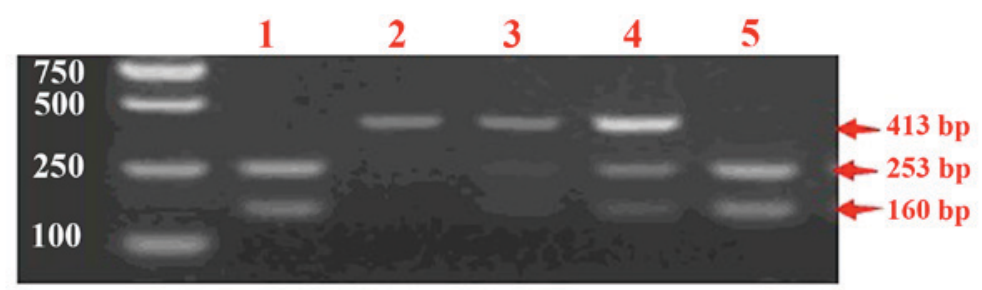

B

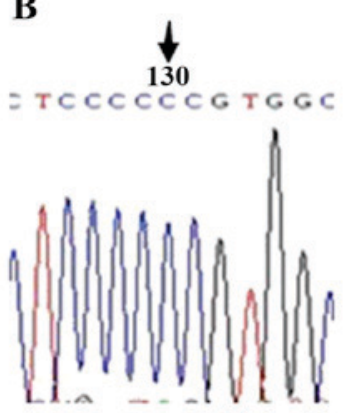

Arg/Arg
C

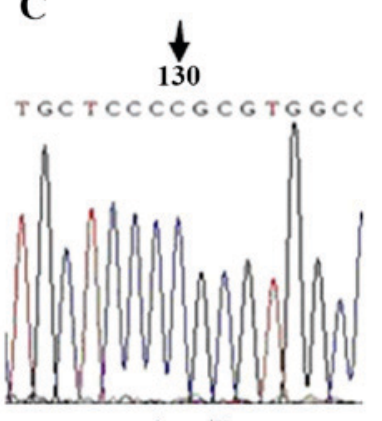

Arg/Pro

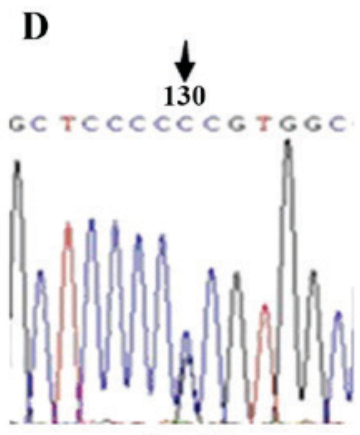

Pro/Pro

Figure 4. Detection of digested PCR products and mutation sites. In the present study, 130 was the position of single nucleotide polymorphism counting from the left of the basic sequence. (A) Electrophoresis analysis of digested PCR products for the alleles Arg/Arg, Arg/Pro and Pro/Pro. (B-D) Sequence analysis of the (B) Arg/Arg, (C) Arg/Pro heterozygous and (D) Pro/Pro genotypes.

papilloma virus (HPV) 16, which would increase their ESCC risk (19).

p53 gene is a tumor-suppressor gene that is associated with cell cycle regulation, DNA repair, cell differentiation, apoptosis and other important biological functions (20). The 72nd codon of the p53 gene in exon 4 codes for arginine (Arg72R) or proline (Pr72P) (21). Previous studies have shown that the 553 Pro72P subtype is more easily located in the nucleus, while 
Table II. Comparative analysis of clinical data in the ESCC and control groups.

\begin{tabular}{|c|c|c|c|c|}
\hline Characteristics & ESCC, n $(\%)$ & Control, n (\%) & P-value & $\chi^{2}$ \\
\hline Total no. of patients & $100(100)$ & $50(100)$ & & \\
\hline Age, years & & & 0.073 & 3.211 \\
\hline$\leq 45$ & $1(1)$ & $3(6)$ & & \\
\hline$>45$ & 99 (99) & $47(94)$ & & \\
\hline Sex & & & 0.857 & 0.033 \\
\hline Male & $91(91)$ & $39(78)$ & & \\
\hline Female & $9(9)$ & $11(22)$ & & \\
\hline Alcohol consumption & & & $<0.001$ & 15.992 \\
\hline No & $13(13)$ & $21(42)$ & & \\
\hline Yes & $87(87)$ & $29(58)$ & & \\
\hline Cigarette smoking & & & $<0.001$ & 11.344 \\
\hline No & $38(38)$ & $34(68)$ & & \\
\hline Yes & $62(62)$ & $16(32)$ & & \\
\hline
\end{tabular}

Numbers in parenthesis indicates constituent ratio of samples. ESCC, esophageal squamous cell carcinoma.

Table III. Comparative analysis of p53 Pro72Arg polymorphism status in ESCC and healthy control samples.

\begin{tabular}{|c|c|c|c|c|c|c|c|c|c|}
\hline \multirow[b]{2}{*}{ Group } & \multicolumn{3}{|c|}{$\begin{array}{c}\text { Genotype } \\
\text { distribution, } \mathrm{n}(\%)^{\mathrm{a}}\end{array}$} & \multirow[b]{2}{*}{$\chi^{2}$} & \multirow[b]{2}{*}{ P-value ${ }^{b}$} & \multicolumn{2}{|c|}{$\begin{array}{c}\text { Allele } \\
\text { distribution, \% }\end{array}$} & \multirow[b]{2}{*}{$\chi^{2}$} & \multirow[b]{2}{*}{ P-value } \\
\hline & Arg/Arg & Arg/Pro & Pro/Pro & & & Arg & Pro & & \\
\hline ESCC & $33^{c}(33.3)^{d}$ & $42(41.7)$ & $25(25)$ & 7.49 & 0.024 & $54.0^{\mathrm{d}}$ & 46.0 & 6.165 & 0.013 \\
\hline Control & $28(56.0 \%)$ & $15(30.0)$ & $7(14.0)$ & & & 71.0 & 29.0 & & \\
\hline
\end{tabular}

${ }^{\text {aP-values with }} \chi^{2}$ test for deviation from Hardy-Weinberg equilibrium are 0.055 and 0.122 for controls and patients with ESCC, respectively. ${ }^{\mathrm{b}} \mathrm{P}$-value from $\chi^{2}$ test performed for comparison of patients with ESCC with controls ${ }^{\mathrm{c}}$ Total number of samples. ${ }^{\mathrm{d}} \mathrm{Numbers}$ in parenthesis indicates the constituent ratio of genotypes or alleles. ESCC, esophageal squamous cell carcinoma.

Table IV. Risk analysis of p53 gene polymorphism and esophageal cancer in Mongolia.

\begin{tabular}{|c|c|c|c|c|c|}
\hline p53 codon 72 genotypes & ESCC, n (\%) & Control, n (\%) & $\chi^{2}$ & P-value & OR $(95 \% \mathrm{Cl})$ \\
\hline Arg/Arg & $33(33.0)$ & $28(56.0)$ & 7.308 & 0.007 & $1.659(1.112-2.474)$ \\
\hline Arg/Pro + Pro/Pro & $67(67.0)$ & $22(44.0)$ & & & \\
\hline
\end{tabular}

ESCC, esophageal squamous cell carcinoma; OR, odds ratio; CI, confidence interval.

the p53 Arg72R subtype is more easily located in the mitochondria under stress (22). Therefore, it is possible that the $\mathrm{p} 53$ Pro72p subtype may more effectively induce gene expression of nuclear DNA compared with the p53 Arg72R subtype (23). The polymorphism of the 72 codon of the p53 gene can affect the induction of cell apoptosis and the repair of damaged DNA, which are functions closely associated with the maintenance of the integrity of the nuclear envelope $(23,24)$. In addition, the polymorphism of the 72 codon of the p53 gene may affect the accumulation of mitochondrial DNA mutations by combining with DNA polymerase $\gamma$ (19). Therefore, the polymorphism of the p53 gene on codon 72 can affect the normal functions of the p53 gene, and may be involved in the prognosis of patients with ESCC.

To the best of our knowledge, the majority of previous Chinese studies have shown that there is an association between the polymorphism of p53 Arg72Pro in Chinese patients with ESCC, and the heterozygous genotype (Arg/Pro) and the mutant homozygous genotype (Pro/Pro) can significantly increase the incidence of esophageal cancer risk (25). The present study 
demonstrated that the allele Pro may increase the risk of ESCC in Mongolian patients by 1.659-fold compared with that of the allele Arg (Table IV). However, the conclusion may be different for different countries and nationalities. For example, the homozygous Pro/Pro polymorphism can increase the risk of esophageal cancer in the population of Korea (26). Notably, another study from USA reported that no association existed between p53 Pro72Arg and ESCC $(27,28)$. In Japan, a previous report revealed that alteration of p53 tumor-suppressor protein was suspected to be the key molecular event in multifocal carcinogenesis (29). In addition, the authors observed markedly high levels of p53 protein accumulation in early ESCC in Japanese alcoholic men (21).

According to recent studies, the susceptible genotype of p53 72 codon appears to be different for different tumors. Buyru's study revealed that there was a significant correlation between the genotype Arg/Arg on p53 72 codon and female breast cancer in the population of Turkey (29). Previous studies (30-32) indicated that the Arg/Arg genotype could increase the risk of HPV-associated tumors. Buller et al (33) demonstrated that the Arg/Pro genotype and borderline ovarian cancer had a close association. Previous studies on Northern Chinese populations revealed that the homozygous genotype Pro/Pro was an independent risk for ESCC, and it could increase the risk of ESCC by 2-fold compared with that of the Arg/Arg genotype (34-37). In the present study, this risk was determined to be 1.659 -fold instead (Table IV).

The present results revealed a significant association between the polymorphism of TP53 codon 72 and the risk of developing ESCC risk in Mongolian patients. These results may be useful for esophageal cancer prevention. In order to unravel the biological progression of ESCC in Mongolian patients, the association of other gene polymorphisms with the risk of ESCC must be explored to display a potential multiplicative gene-gene interaction.

In conclusion, the present study revealed that alcohol drinking and cigarette smoking could increase the risk of ESCC in Mongolian patients, and suggested the need to advocate for a healthy lifestyle among the Mongolian population. Our results support previous conclusions suggesting different behavior of the p53 Pro72Arg alleles in different cancer types and ethnicities in ESCC. These results may provide clinical support for survival and chemo/radiotherapies of ESCC, although further studies to analyze the effect of p53 codon 72 genotype polymorphism on patients are required. Animal models may help to unravel the function of mutations in the codon 72 of the p53 gene in the process of ESCC development.

\section{Acknowledgements}

The present study was supported in part by the National Natural Science Foundation of China (grant no. 81450036 awarded to Y.W. and grant no. 81260196), Scientific Research Projects in Universities of Inner Mongolia Autonomous Region (grant no. NJZZ14271) and Natural Science Foundation of Inner Mongolia Autonomous Region (grant no. 2013MS1176). The authors thank the Department of General Surgery of the Affiliated Hospital of Inner Mongolia University for Nationalities, the staff members of the Oncology Hospital of
Khorchin and Mrs Guoli Liu (Animal Laboratory of Affiliated Hospital of Inner Mongolia University for the Nationalities) for their help in sample collection. The authors also thank Dr Haihua Bai and Mr Wenyan Huo (Centre for Cellular and Molecular Biology of Inner Mongolia University for the Nationalities) for the collection of DNA samples from healthy individuals. In addition, the authors thank Beijing Genomics Institute for their help in validating the present results by providing gene sequencing services.

\section{References}

1. Pennathur A, Gibson MK, Jobe BA and Luketich JD: Oesophageal carcinoma. Lancet 381: 400-412, 2013.

2. Yang J, Liu B, Li W, Xiong H, Qiu H, Fu Q, Chen B, Hu G and Yuan X: Association of $\mathrm{p} 53$ and MDM2 polymorphisms with risk of human papillomavirus (HPV)-related esophageal squamous cell carcinoma (ESCC). Cancer Epidemiol 37: 629-633, 2013

3. Jemal A, Bray F, Center MM, Ferlay J, Ward E and Forman D: Global cancer statistics. CA Cancer J Clin 61: 69-90, 2011.

4. Enzinger PC and Mayer RJ: Esophageal cancer. N Engl J Med 349: 2241-2252, 2003.

5. Islami F, Boffetta P, Ren JS, Pedoeim L, Khatib D and Kamangar F: High-temperature beverages and foods and esophageal cancer risk-a systematic review. Int J Cancer 125: 491-524, 2009.

6. Kamangar F, Chow WH, Abnet CC and Dawsey SM: Environmental causes of esophageal cancer. Gastroenterol Clin North Am 38: 27-57, vii, 2009.

7. Zhang HZ, Jin GF and Shen HB: Epidemiologic differences in esophageal cancer between Asian and Western populations. Chin J Cancer 31: 281-286, 2012.

8. Gong Jinshan, Ao Shuyun and Deng Ao Qimuge: Related research of Mongolia national diet and esophageal cancer in Inner Mongolia area of Tongliao. Chinese Medical Guide: 450-451, 2013.

9. Davidoff AM, Iglehart JD and Marks JR: Immune response to p53 is dependent upon p53/HSP70 complexes in breast cancers. Proc Natl Acad Sci USA 89: 3439-3442, 1992.

10. Vogiatzi P, Vindigni C, Roviello F, Renieri A and Giordano A: Deciphering the underlying genetic and epigenetic events leading to gastric carcinogenesis. J Cell Physiol 211: 287-295, 2007.

11. Li Y: Clinical study of reflux esophagitis in Mongolian. Inner Mongol J Med 02: 208-209, 2014.

12. Shimada H, Nabeya Y, Okazumi S, Matsubara H, Funami Y, Shiratori T, Hayashi H, Takeda A and Ochiai T: Prognostic significance of serum p53 antibody in patients with esophageal squamous cell carcinoma. Surgery 132: 41-47, 2002.

13. Wang Z, Li X, Gao F, et al: Analysis of the incidence of malignant tumors in Hami area from 2010 to 2012. Xinjiang Med 10: 1501-1504, 2015

14. Wu M, Zhao JK, Hu XS, Wang PH, Qin Y, Lu YC, Yang J, Liu AM, Wu DL, Zhang ZF, et al: Association of smoking, alcohol drinking and dietary factors with esophageal cancer in high- and low-risk areas of Jiangsu Province, China. World J Gastroenterol 12: 1686-1693, 2006.

15. Sakata K, Hoshiyama Y, Morioka S, Hashimoto T, Takeshita T and Tamakoshi A; JACC Study Group: Smoking, alcohol drinking and esophageal cancer: Findings from the JACC Study. J Epidemiol 15 (Suppl 2): S212-S219, 2005.

16. Yang CX, Wang HY, Wang ZM, Du HZ, Tao DM, Mu XY, Chen HG, Lei Y, Matsuo K and Tajima K: Risk factors for esophageal cancer: A case-control study in South-western China. Asian Pac J Cancer Prev 6: 48-53, 2005.

17. Castelli E, Hrelia P, Maffei F, Fimognari C, Foschi FG, Caputo F, Cantelli-Forti G, Stefanini GF and Gasbarrini G: Indicators of genetic damage in alcoholics: Reversibility after alcohol abstinence. Hepatogastroenterology 46: 1664-1668, 1999.

18. Zhao Y, Wang F, Shan S, Zhao Y, Qiu X, Li X, Jiao F, Wang J and Du Y: Genetic polymorphism of p53, but not GSTP1, is association with susceptibility to esophageal cancer risk-a meta-analysis. Int J Med Sci 7: 300-308, 2010.

19. Altilia S, Santoro A, Malagoli D, Lanzarini C, Ballesteros Álvarez JA, Galazzo G, Porter DC, Crocco P, Rose G, Passarino G, et al: TP53 codon 72 polymorphism affects accumulation of mtDNA damage in human cells. Aging (Albany NY) 4: 28-39, 2012. 
20. Chen H, Yang X and Wang Z: Association between p53 Arg72Pro polymorphism and recurrent pregnancy loss: An updated systematic review and meta-analysis. Reprod Biomed Online 31: 149-153, 2015.

21. Papadakis EN, Dokianakis DN and Spandidos DA: p53 codon 72 polymorphism as a risk factor in the development of breast cancer. Mol Cell Biol Res Commun 3: 389-392, 2000.

22. Thomas M, Kalita A, Labrecque S, Pim D, Banks L and Matlashewski G: Two polymorphic variants of wild-type p53 differ biochemically and biologically. Mol Cell Biol 19: 1092-1100, 1999.

23. Pereira L, Carvalho MR, Fonseca CG, Lima SS, Cerqueira EM, Jorge W and Castro MC: Influence of Arg72Pro polymorphisms of TP53 on the response of buccal cells to radiotherapy. Genet Mol Res 10: 3552-3558, 2011.

24. Vogelstein B and Kinzler KW: p53 function and dysfunction. Cell 70: 523-526, 1992.

25. Piao JM, Kim HN, Song HR, Kweon SS, Choi JS, Yoon JY, Chung IJ, Kim SH and Shin MH: p53 codon 72 polymorphism and the risk of esophageal cancer: A Korean case-control study. Dis Esophagus 24: 596-600, 2011.

26. Hamajima N, Matsuo K, Suzuki T, Nakamura T, Matsuura A, Hatooka S, Shinoda M, Kodera Y, Yamamura Y, Hirai T, et al: No associations of p73 G4C14-to-A4T14 at exon 2 and p53 Arg72Pro polymorphisms with the risk of digestive tract cancers in Japanese. Cancer Lett 181: 81-85, 2002.

27. Liu G, Cescon DW, Zhai R, Zhou W, Kulke MH, Ma C, Xu W, Su L, Asomaning K, Heist RS, et al: p53 Arg72Pro, MDM2 T309G and CCND1 G870A polymorphisms are not associated with susceptibility to esophageal adenocarcinoma. Dis Esophagus 23: 36-39, 2010.

28. Aida J, Yokoyama A, Shimomura N, Nakamura K, Ishikawa N, Terai M, Poon S, Matsuura M, Fujiwara M, Sawabe M, et al: Telomere shortening in the esophagus of Japanese alcoholics: Relationships with chromoendoscopic findings, ALDH2 and ADH1B genotypes and smoking history. PLoS One 8: e63860, 2013.

29. Buyru N, Altinisik J, Demokan S and Dalay N: p53 genotypes and haplotypes associated with risk of breast cancer. Cancer Detect Prev 31: 207-213, 2007.

30. Zehbe I, Voglino G, Wilander E, Genta F and Tommasino M Codon 72 polymorphism of $\mathrm{p} 53$ and its association with cervical cancer. Lancet 354: 218-219, 1999.

31. Jee SH, Lee JE and Park JS: Polymorphism of codon 72 of p53 and environmental factors in the development of cervical cancer Int J Gynaecol Obstet 80: 69-70, 2003.
32. Buller RE, Sood A, Fullenkamp C, Sorosky J, Powills K and Anderson B: The influence of the p53 codon 72 polymorphism on ovarian carcinogenesis and prognosis. Cancer Gene Ther 4: 239-245, 1997.

33. Buller RE, Shahin MS, Holmes RW, Hatterman M, Kirby PA and Sood AK: p53 Mutations and microsatellite instability in ovarian cancer: Yin and yang. Am J Obstet Gynecol 184: 891-903, 2001.

34. Cai L, Mu LN, Lu H, Lu QY, You NC, Yu SZ, Le AD, Zhao J, Zhou XF, Marshall J, et al: Dietary selenium intake and genetic polymorphisms of the GSTP1 and p53 genes on the risk of esophageal squamous cell carcinoma. Cancer Epidemiol Biomarkers Prev 15: 294-300, 2006.

35. Zhang L, Xing D, He Z and Lin D: p53 gene codon 72 polymorphism and susceptibility to esophageal squamous cell carcinoma in a Chinese population. Zhonghua Yi Xue Yi Chuan Xue Za Zhi 19: 10-13, 2002 (In Chinese).

36. Hong Y, Miao X, Zhang X, Ding F, Luo A, Guo Y, Tan W, Liu Z and Lin D: The role of P53 and MDM2 polymorphisms in the risk of esophageal squamous cell carcinoma. Cancer Res 65: 9582-9587, 2005.

37. Ge H, Cao YY, Chen LQ, Wang YM, Chen ZF, Wen DG, Zhang XF, Guo W, Wang N, Li Y and Zhang JH: PTEN polymorphisms and the risk of esophageal carcinoma and gastric cardiac carcinoma in a high incidence region of China. Dis Esophagus 21: 409-415, 2008. 